\title{
Rabaska
}

Revue d'ethnologie de l'Amérique française

"Le fléché, bien plus qu'une ceinture ! " Exposition présentée à la Maison des jésuites de Sillery, du 19 mars au 14 décembre 2014, Québec (Québec). Commissaires de l'exposition : YVETTE Michelin et ClAUde CoRRIVEAU

\section{Suzanne Marchand}

Volume 12, 2014

URI : https://id.erudit.org/iderudit/1026826ar

DOI : https://doi.org/10.7202/1026826ar

Aller au sommaire du numéro

Éditeur(s)

Société québécoise d'ethnologie

ISSN

1703-7433 (imprimé)

1916-7350 (numérique)

Découvrir la revue

Citer ce compte rendu

Marchand, S. (2014). Compte rendu de ["Le fléché, bien plus qu’une ceinture ! » Exposition présentée à la Maison des jésuites de Sillery, du 19 mars au 14 décembre 2014, Québec (Québec). Commissaires de l'exposition : YvETTE Michelin et ClAUde CORRIVEAU]. Rabaska, 12, 327-328.

https://doi.org/10.7202/1026826ar d'utilisation que vous pouvez consulter en ligne. 


\section{Vieillir au féminin}

Depuis le début du $\mathrm{Xx}^{\mathrm{e}}$ siècle, les publicités diffusées dans les revues féminines insistent tout particulièrement sur le devoir de paraître et rester jeune. Nulle n'est censée laisser paraître son âge réel. Vieillir n'a décidément jamais eu le même sens, ni les mêmes conséquences pour les femmes que pour les hommes. Pendant des siècles en Occident, la ménopause a été perçue comme une période dangereuse et critique pour la santé des femmes. Le terme « ménopause » serait apparu en 1823, mais jusqu'au début du Xx ${ }^{\mathrm{e}}$ siècle, on utilisait plutôt l'expression « retour d'âge » pour évoquer cette étape de la vie des femmes où de nombreux problèmes et malheurs physiques étaient censés s'abattre sur elles. On utilisait le millepertuis pour traiter la dépression, les symptômes de la ménopause et l'anxiété.

Voilà donc un regard fort intéressant et très bien documenté sur une période de la vie trop peu étudiée. L'ethnologue Suzanne Marchand met en lumière la situation des personnes âgées au Québec et cette exposition nous permet d'en saisir les différences d'un siècle à l'autre.

LOUISE DÉCARIE

Société québécoise d'ethnologie

"Le fléché, bien plus qu'une ceinture! " Exposition présentée à la Maison des jésuites de Sillery, du 19 mars au 14 décembre 2014, Québec (Québec). Commissaires de l'exposition: Yvette Michelin et Claude Corriveau.

Conçue par l'ethnomuséologue Claude Corriveau et la flécherande Yvette Michelin, cette exposition nous invite à découvrir le merveilleux monde du fléché. Un monde où la ceinture fléchée occupe bien sûr une grande place, mais où d'autres productions issues de ce savoir-faire particulier sont aussi mises en valeur. Et c'est là sans doute la plus grande qualité de cette exposition car, comme le dit si bien son titre : «Le fléché, c'est bien plus qu'une ceinture !» On peut donc y admirer plusieurs œuvres d'art et accessoires réalisés grâce à cette technique qui permet de créer des pointes de flèches, des éclairs ou des losanges simplement en croisant des fils avec les doigts.

L'exposition comporte quatre volets. Un premier volet retrace l'histoire du fléché à l'aide de reproductions d'aquarelles, de gravures et de peintures issues des XVII ${ }^{\mathrm{e}}, \mathrm{XVIII}^{\mathrm{e}}$ et $\mathrm{XIX}^{\mathrm{e}}$ siècles. Plusieurs ceintures fléchées de la fin du XVIII ${ }^{\mathrm{e}}$ siècle et du début du XIX ${ }^{\mathrm{e}}$ siècle provenant de diverses collections personnelles et muséales, des pièces rares et peu souvent exposées, y sont aussi présentées. Un deuxième volet est consacré aux tentatives de mise en valeur et d'enseignement du fléché au Québec au cours de la première 
moitié du Xxe siècle, à la suite des recherches entreprises par Édouard-Zotique Massicotte et Marius Barbeau au cours des années 1920 et 1930. On peut y apercevoir les principales artisanes ayant contribué à la survie de cet art textile alors menacé de disparition, dont Élisabeth Mireault, Cécile Barot, Germaine Galerneau et Flore-Ida Chevalier. Ce volet se clôt sur Expo 67, un événement qui aurait semble-t-il beaucoup contribué à la renaissance du fléché au Québec au cours des années 1970. Le troisième volet traite de la relève et de la transmission de ce savoir-faire à partir des années 1970. C'est dans cette partie de l'exposition qu'on trouve des œuvres contemporaines réalisées grâce à la technique du fléché, dont plusieurs murales très impressionnantes, un petit tableau et quelques accessoires vestimentaires (ceintures, foulards, chapeaux, sacs), œuvres de Denise Verdeau-Hemlin, Jocelyne Venne, Pierre Bélanger, Yvette Michelin, Véronique L. Hamelin, Nicole Bourgault, Lauréat Roberge et Estelle Boisvert. S'ajoute à cette section de l'exposition une courte présentation vidéo dans laquelle Yvette Michelin explique les principales étapes de réalisation d'une pièce et insiste sur ce qui distingue le fléché des autres techniques de tissage aux doigts utilisées dans le monde. Il est même possible de tenter l'expérience puisqu'une petite pièce déjà montée est disponible pour ceux et celles qui voudraient s'y essayer. Enfin, un dernier volet est consacré à l'utilisation du fléché à des fins protocolaires et honorifiques. On peut y apercevoir des photographies de personnalités connues recevant ou arborant fièrement une ceinture ou un foulard réalisé à l'aide de cette technique, ainsi que quelques pièces d'apparat utilisées dans le cadre d'événements populaires comme le Carnaval de Québec.

Si j'ai été séduite par certaines des œuvres présentées, notamment les ceintures fléchées anciennes et une œuvre magnifique de Monique GenestLeblanc, j'aurais apprécié qu'on insiste davantage sur la complexité du savoir-faire. Mais sans doute cet aspect a-t-il été traité lors des nombreuses démonstrations de fléché prévues à l'horaire de cette exposition auxquelles je n'ai malheureusement pas pu assister.

Bien que de dimension réduite, cette exposition réussit à nous faire voyager dans le temps en nous livrant à grands traits les principaux tournants de l'histoire de cette technique transmise de génération en génération depuis plus de deux siècles au Québec. Elle nous permet aussi de partager la passion d'Yvette Michelin pour cet art textile auquel elle a consacré une grande partie de sa vie et qui lui a valu de remporter le prix du Patrimoine de la Ville de Québec dans la catégorie « Porteurs de tradition » en 2013.

SuZANne Marchand Société québécoise d'ethnologie 